\title{
Harvesting forest biomass reduces wildfire fuel
}

Understory trees and shrubs that once were destroyed by frequent, low-Intensity fires have survived and grown, resulting in dense stands of trees and shrubs. Forest fires can cllmb these "fuel ladders" into the crowns of larger trees. (Shown here is a 1988 prescrlbed burn in the Santa Monica mountains.)

Gary Nakamura

\begin{abstract}
Years of drought, tree mortality due to insects and the successful suppression of forest fires over the past century have created dense stands of trees and shrubs. This buildup is potentially dangerous as a reservoir of fuel for uncontrollable wildfires in California forests. The advent of biomass power plants has made removal of excess plant material from the forest economically feasible, reducing wildfire hazard and preparing fire-adapted forests for reintroduction of prescribed fire.
\end{abstract}

The health of California's interior forests is threatened by the presence of too many trees in too many places, created in part by successful fire-suppression activities in fire-adapted ecosystems such as the Sierra Nevada mixed-conifer forest. At risk are the habitats of many wildlife species, including the California spotted owl, as well as homes, watershed, health and the aesthetic values associated with forests. Understory trees and shrubs that once were destroyed by frequent, low-intensity fires have survived and grown, resulting in dense stands of trees and shrubs, which can serve as fuel ladders into the crowns of larger trees. While fires on or near the ground are controllable, fires in the tree crowns are intense and destructive. The presence of such hazardous fuel levels, combined with an increased risk of fire starts due to increasing development in the wildlands and frequent hot, dry, windy conditions, can turn controllable fires into uncontrollable, catastrophic wildfires such as the 1992 Fountain fire, 1992 Cleveland fire and 1994 Cottonwood fire.

Fuel levels and fire hazard can be alleviated by thinning small trees from the forest, reducing wildfire intensity from one that requires bulldozers to one that can be controlled with hand tools. Until recently, small trees were not processed into any commercially valuable product and thinning represented a net cost of a few hundred dollars per acre. Thinning consisted of cutting the main stem and lopping off branches, leaving the material on the ground, where it exacerbated the fuel and fire hazard while attenuating the intertree competition for water and nutrients. Given its high cost and mixed benefits, precommercial thinning has not been widely applied.

Harvesting small trees became economically feasible in the mid-1980s, when a market developed for wood fuel for electric power plants. The Public Utilities Regulatory Policy Act of 1978 encouraged the use of domestic and renewable resources such as forest biomass for electrical power generation. By 1990, 975 megawatts of power had been produced using 8 million bone-dry tons (BDT) of biomass annually, of which 2.25 million BDT came from forests and the forest products industry.

\section{Forest biomass}

Forest biomass refers to all aboveground plant materiat. It can include small or dead trees, shrubs, and the tops, foliage, or limbs of large commercially valuable trees. Because these materials are typically left on the forest floor to decompose, biomass 

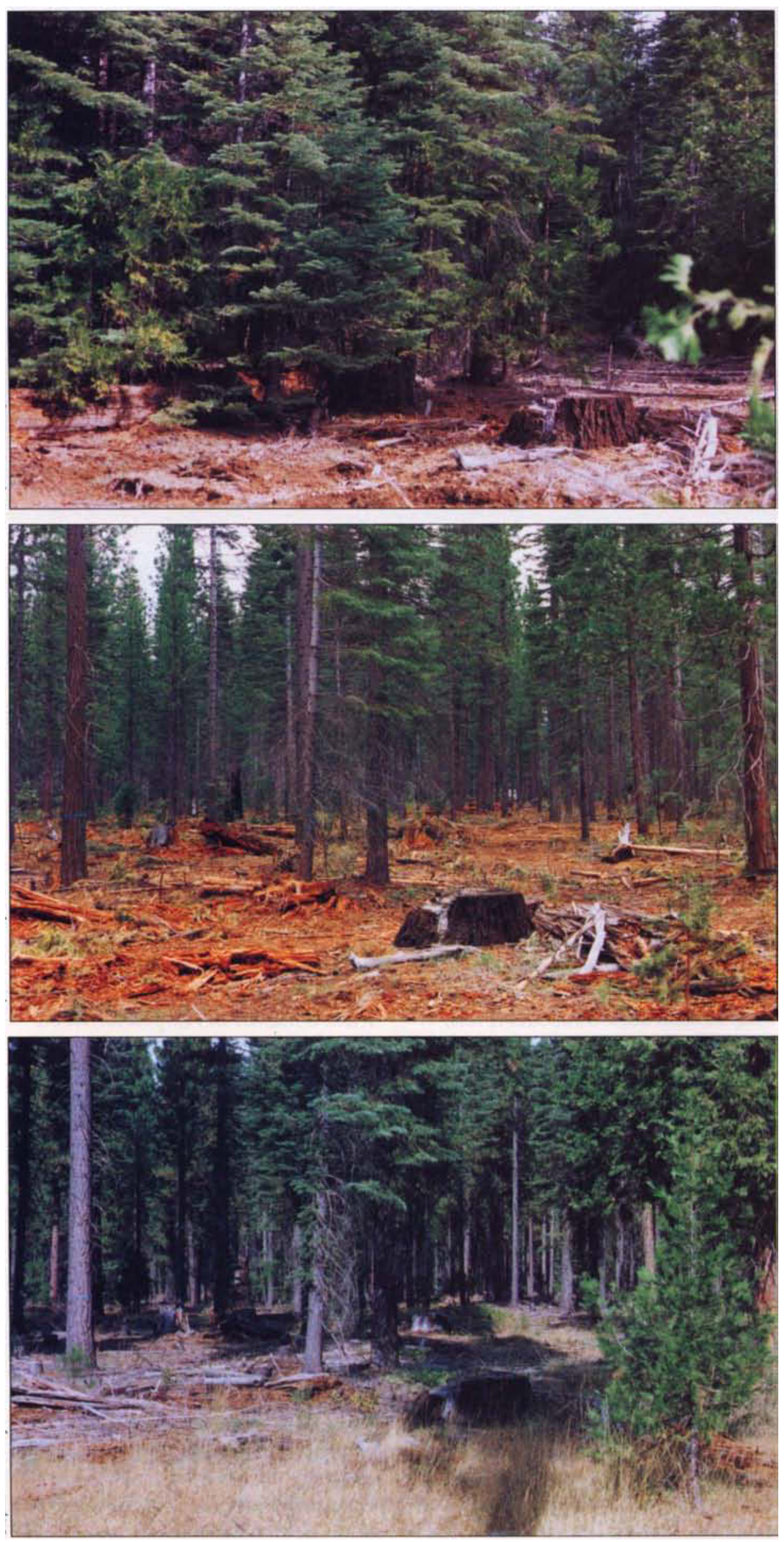

Top left, mixed-conifer forest stand in 1988, typical of stands that would be considered for biomass harvesting to reduce fuel levels and fire hazard, and improve the health of the thinned stand. The biomass in trees 7 inches in diameter at breast height (DBH) and smaller is 26 bone-dry tons per acre.

Middle left, view of stand immediately following a biomass harvest of trees 7 inches DBH and smaller. Foresters considered tree condition, species, size, and spacing before marking "reserve trees" with blue paint.

Lower left,view of stand 7 years after harvest, 1994. Note the growth of the incense cedar in the lower right and the extent to which the forest has filled in with foliage and understory plants.

harvesting represents a broadening of forest materials that can be used. Operationally, biomass harvesting is equivalent to whole-tree harvesting.

Fuel from sawmills (sawdust, trimmings) and agricultural operations (prunings, nutshells) are residues obtainable at low or no cost other than hauling, whereas forest biomass is the most expensive fuel. In 1992, prices of $\$ 35$ to $\$ 40$ per BDT just covered the cost of harvesting, chipping and hauling from the forest to the power plant, bringing little or no profit to the forest landowner. Although paper-pulp chips represent a higher value product, they require more processing and usually longer hauls to pulp mills. Whether a financial gain or loss is realized from biomass harvesting depends upon the tons per acre available for harvest, site conditions (slope, tree sizes), haul distance to power plant and current markets for wood chips.

\section{Biomass harvest operations}

The mechanization of biomass harvesting has made it both economically feasible and silviculturally useful useful in reducing intertree competition and improving the growth and condition of trees. Feller-bunching machines travel to each tree and sever the stem at ground line with hydraulic shears, much like large pruning shears with 14 - to 20 -inch-diameter capacity. These machines gather several trees into bunches, which are then laid on the ground to dry. This ability to 
gather and handle trees in bunches makes it economically feasible to remove biomass for processing into fuel chips or other products. If the trees were simply cut or killed, but not removed from the forest, fuel and fire hazard would increase along with insect activity and the treatment would not be as beneficial silviculturally.

Following a week or two of drying to reduce moisture content, bunches are dragged by tractor to an in-woods chipping machine for processing into fuel chips. The momentum imparted by the rotating chipper head hurls the chips into vans for transport to power plants.

Feller-bunching machines harvest whole trees, including branches, stem and leaves, removing their organic matter and nutrients from the forest. Variations include delimbing heads, which cut trees, then remove the limbs and foliage at the stump to be recycled into the soil. Feller-bunching heads can be mounted on booms, which can reach for trees, obviating the need to drive up to each tree. Forwarders that pick up logs and load them onto wagons reduce the road network necessary for harvest operations.

\section{Forest stand considerations}

Densely stocked stands are suitable candidates for biomass harvesting for three reasons: (1) reducing intertree competition will improve the vigor of the residual trees and their resistance to insects and drought; (2) there is sufficient biomass per acre to make harvesting and hauling economically feasible; and (3) such levels of biomass constitute a severe fire hazard.

For an operation to be economical, 25 green tons (approximately 12.5 $\mathrm{BDT}$ ) of biomass are required from each acre. Trees harvested for biomass range in size from 2-inch DBH (diameter breast height measured at 4.5 feet above the ground surface) and a height of 15 feet, to 8-inch DBH and 40 feet high. These trees, prior to the mechanization of biomass harvesting, were not economical or practical to treat. Larger trees are left to grow or be harvested for higher value products such as lumber or paper-pulp chips.
Harvesting larger trees for higher value products is often combined with break-even or uneconomical biomass harvesting, essentially investing some of the value of the commercial harvest in thinning and improving the health of the stand.

The quantity of biomass that makes such a harvest economical is also the level at which fuel loading makes wildfire suppression difficult. Biomass harvesting can reduce the fuel load to $5 \mathrm{BDT} / \mathrm{ac}$, where a fire could be controlled with hand tools because intensity and flame length are low.

Using current equipment, efficient and safe biomass harvesting is usually done on slopes less than $30 \%$. Equipment exists for steep slopes, but operating costs are higher, and it is more difficult to control damage to crop trees that are not removed.

In addition to reducing competition and fire fuel, biomass harvesting can affect the type and extent of understory vegetation and concomitant changes in animal habitat. Thinning trees to open the understory to light and to reduce competition for soil moisture can promote development of grass and shrub species and the animals that use them.

\section{Potential adverse impacts}

Because feller-bunching machines must travel to each tree that is to be harvested, soil compaction is a concern. However, compaction can be mitigated by driving equipment over slash (tree limbs, foliage) or forest floor litter and duff (decaying plant material), rather than bare soil. Designated skid trails and limits on traffic over wet soils in the early spring and fall also could reduce areas of significant compaction.

Removal of whole trees raises concerns about depleting soil nutrients. Unlike tropical forest ecosystems, which retain the major portion of ecosystem nutrients in the standing biomass, temperate forest ecosystems retain 80 to $90 \%$ of their total nutrients in the soil, with 10 to $20 \%$ evenly divided between standing biomass and leaves and branches on the forest floor. Table 1 presents the biomass and nutrient distribution for a typical mixedconifer forest prior to biomass harvesting -850 trees per acre less than 7 inches in diameter; 150 trees per acre greater than 7 inches in diameter; a forest floor 2 to 3 inches thick, consisting of leaves, twigs, and branches; and a productive forest soil 3.3 feet deep.

Biomass harvesting would remove most of the trees less than 7 inches in diameter, and some of the larger trees, depending upon plans for growing the thinned stand and future regeneration. Thinning intensity could vary, leaving denser spots for wildlife cover and thinner areas where fire risk is greater.

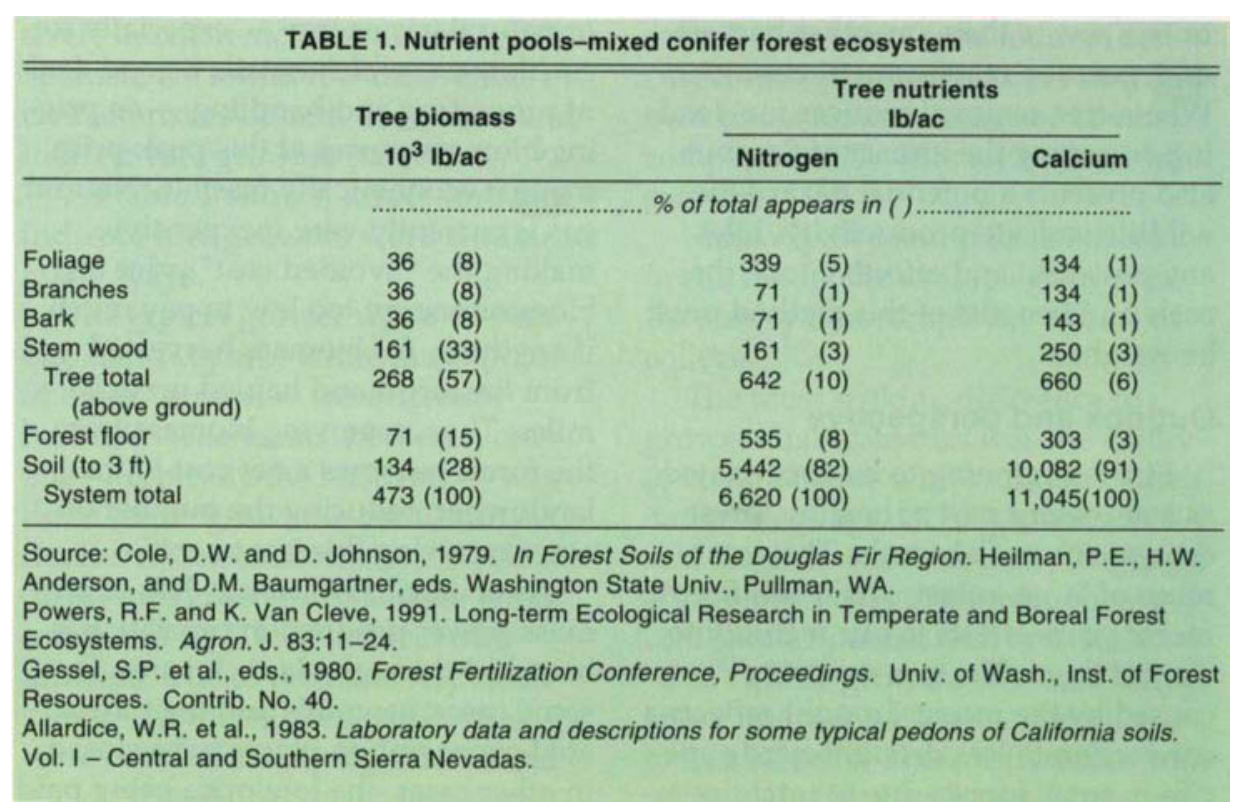


Based on table 1, biomass harvesting of all trees less than 7 inches diameter would remove about 125 pounds nitrogen per acre, $19 \%$ of the total in the biomass component but only $2 \%$ of the ecosystem total.

Table 2 shows the rates at which nutrients are added to an ecosystem, replenishing nutrients that are removed during biomass and other harvest activities. Concentration and quantity of precipitation vary with air quality. Smoggy air produces precipitation higher in nitrogen and sulfur oxides. The air over western U.S. forests is relatively clean, as reflected in the rates. Weathering is the dissolution of primary rock minerals such as feldspar and biotite into their elemental components. Mineralization is the biological decomposition of soil organic matter and forest litter by insects, fungi and bacteria into compounds and elements that can be absorbed by plants.

As presently practiced, biomass harvests to reduce fuel and fire hazard would occur infrequently, every 15 to 20 years. In this way, nutrients removed during a harvest can be replenished before the next harvest, except possibly at sites where soils are thin and infertile and a higher proportion of the ecosystem's nutrients are in the standing vegetation.

The potential impacts on wildlife from biomass harvesting are no more or less severe than any other harvest or vegetation management practice. Whole-tree removal reduces fuel loading, lessening the impact of fire, but also presents a potential hazard for wildlife and site productivity. Like any powerful and effective tool, the costs and benefits of this method must be weighed.

\section{Outlook and perspective}

Fire is beginning to be appreciated as a necessary part of healthy forest ecosystems in California. The occurrence of large, catastrophic wildfires in recent years attests to our inability to control them. The tree mortality caused by the recent drought reflects a conversion to less drought-hardy species in some forests due to total fire ex-
TABLE 2. Nutrient inputs to the soil

\begin{tabular}{lcc}
\hline \hline & Nitrogen & Calcium \\
\hline Precipitation & 2 (1 to 4$)$ & 7 lb/ac/yr .................. \\
Weathering & Trace & $12(2$ to 23$)$ \\
Mineralization & 52 & - \\
$\quad$ Total & 54 & 20 \\
\hline
\end{tabular}

Source: Powers, R.F., 1974. Mineral cycling in temperate forest ecosystems. N. Cal. SAF/UC Coop. Ext. Field School on Forest Soils, Redding, CA. Powers, R.F., 1990. Nitrogen mineralization along an altitudinal gradient: interactions of soils temp. moisture, and substrate quality. Forest Ecology and Management, 30:19-29.

clusion. Trees killed by drought become fuel for the next wildfire so we must reduce these fuels in some manner, possibly using fire itself. We cannot, however, safely and controllably reintroduce fire to forest ecosystems given the current levels of fuels built up from decades of fire exclusion. Forest biomass harvesting represents a method for reducing fuel levels and fire hazard for some sites and stand conditions.

The cost of removing biomass can be offset by selling it as fuel, paper pulp chips or other products. The Public Utilities Regulatory Policy Act of 1978 encouraged development of biomass power plants by locking in for 10 years the price paid for power at the "avoided cost" of building new power plants in 1978 when petroleum prices were high. Biomass power is inherently more expensive than petroleum or natural gas energy - especially forest biomass, which entails a good deal of processing and handling - so pricing biomass power at this peak price made it economically feasible. Natural gas is currently very inexpensive, making the "avoided cost" price for biomass energy too low to pay much, if anything, for biomass harvested from the forest and hauled up to 50 miles. Thus, removing biomass from the forest becomes a net cost to the landowner, reducing the number of acres receiving this treatment.

As of April 1996, about 30\% of biomass power production capacity has been lost through plant closures. In some cases, sawmills and their associated cogeneration plants have closed; in other cases, the low price being paid for electric power has made biomass power uncompetitive. To maintain renewable resource energy generators like wind, geothermal, solar, hydro and biomass, Assembly Bill 1202 proposes that no less than $1.5 \%$ of the electricity supplied and consumed in the state come from biomass power plants. This represents the biomass power production in early 1994. Indirect benefits of biomass power production are improved air quality from reduction of open air burning; agricultural waste management; less severe forest fires; preservation of urban landfill space by redirecting wood waste to power plants.

Mechanization of harvesting and processing has made biomass harvesting economically and operationally feasible, hastening the day when tasks like timber falling will be replaced by high skill, higher paying jobs required for mechanized harvesting.

As increasing urbanization, auto emissions and industry in rural and forested areas degrade air quality, forest managers are becoming more restricted in the use of prescribed burning to reduce fuel levels. Harvest and removal of forest biomass would reduce the amount of material that would require prescribed burning.

As a renewable energy source, biomass also may offer opportunities to displace carbon emissions from fossil fuel combustion. Carbon dioxide released by burning or decay of plant material can be "recycled" through photosynthesis as forests grow and store cellulose and other organic materials. Biomass plantations of woody and herbaceous plants could be grown to sequester carbon, reducing carbon dioxide input to the atmosphere until it is burned as fuel for power generation. It is sobering, however, to consider that it would require 70 million acres (California is 100 million acres) of productive land to grow sufficient biomass to offset $20 \%$ of current (1992) U.S. fossil fuels emissions, about $4.4 \%$ of global fossil fuel emissions.

G. Nakamura is Area Forestry Specialist, UC Cooperative Extension, Redding. 